\title{
Teatralidade(s) na pesquisa acadêmica: o espaço entre a dramaturgia e a encenação
}

\author{
Teatralidad(es) en la búsqueda académica: el espacio entre la \\ dramaturgia y la puesta en escena
}

\section{Theatricality(ties) in academic research: the space between dramaturgy and staging}

\author{
Lic. Marcos Kuszner dos Santos ${ }^{1}$ \\ Dra. Fernanda Vieira Fernandes ${ }^{2}$
}

\begin{abstract}
Resumo
O artigo a ser apresentado versará sobre as práticas dos integrantes do projeto de pesquisa "Leituras do Drama Contemporâneo" da Universidade Federal de Pelotas (UFPel). A proposta surgiu a partir do anseio de ampliar os conhecimentos acerca da dramaturgia contemporânea, que não é amplamente contemplada no currículo da Licenciatura em Teatro da UFPel, visto que o mesmo compreende uma gama muito extensa de conteúdos, que abarca desde o que se entende por teatro na pré-história até a contemporaneidade. $\mathrm{O}$ grupo se propõe a estudar a literatura dramática produzida a partir do fim do século XX até os dias de hoje, realizando leituras dramáticas abertas à comunidade (acadêmica ou não) no encerramento de cada ciclo de estudo (executado no pequeno grupo) de peça e/ou autor. Antes do surgimento desta iniciativa, no curso de Teatro, não se faziam leituras dramáticas apenas para conhecimento de textos com periodicidade definida. O objetivo das leituras públicas é trazer ao conhecimento das pessoas a existência das peças e de seus autores. Para tal, os integrantes do projeto (todos acadêmicos de Teatro somados à coordenadora, também professora do curso) possuem liberdade para organizar as formas como explorarão os textos. $\mathrm{O}$ artigo pretende investigar a leitura dramática como um ponto entre a dramaturgia enquanto literatura e encenação, analisando o conceito de teatralidade na sistematização e realização das leituras dramáticas realizadas pelo grupo até então.
\end{abstract}

Palavras-Chave: dramaturgia contemporânea; encenação, leitura dramática; teatralidade.

\section{Resumen}

El artículo presentado atraviesa el estudio respecto a las prácticas de los participantes del proyecto de búsqueda "Lecturas del Drama Contemporáneo" de la Universidad Federal de Pelotas (UFPel).La propuesta surgió desde el deseo en agrandar los conocimientos acerca de la dramaturgia contemporánea, que en general no es contemplado en el plan de estudios de la Licenciatura Teatral de la UFPel, teniendo en cuenta que el mismo

\footnotetext{
${ }^{1}$ (Licenciando em Teatro - Bolsista PBIP UFPel; Universidade Federal de Pelotas - UFPel; Pelotas, Rio Grande do Sul, Brasil; marcos.kuszner@gmail.com)

2 (Doutora em Letras; Programa de Pós-graduação em Letras - UFRGS; Porto Alegre, Rio Grande do Sul, Brasil; Docente do Curso de Teatro-Licenciatura - Universidade Federal de Pelotas; Pelotas, Rio Grande do Sul, Brasil; nvnandes@gmail.com)
} 
comprende una gama muy extensa en sus contenidos, abarca desde lo que se comprende por teatro en la prehistoria hasta la contemporaneidad hastas los días actuales, realizando lecturas dramáticas abiertas a la comunidad (académica o no) en el cierre de cada ciclo de estudio (ejecutado en el pequeño grupo) de la obra o autor. El grupo se propone a estudiar la literatura dramática producida en finales del siglo XX hasta los días actuales. Antes del surgimiento de esta iniciativa, en el curso de Teatro, no se hacían lecturas dramáticas apenas para el conocimiento de los textos con periodicidad definida. El objetivo de las lecturas públicas es de traer conocimiento a las personas de la existencia de las obras y de sus autores. Para tal, los componentes del proyecto (compuesto por académicos de Teatro sumados a la coordinadora, también profesora del curso) poseen libertad para ordenar las formas de explorar los textos. El artículo pretende investigar la lectura dramática como un punto entre la dramaturgia en cuanto literatura y la puesta en escena, con una análisis respecto el concepto de teatralidad en la sistematización y realización de las lecturas dramáticas realizadas por el grupo hasta entonces.

Palabras claves: dramaturgia contemporánea: puesta en escena, lectura dramática; teatralidad.

\begin{abstract}
The article to be introduced will deal with the practices by members of the research project "Readings of contemporary drama" in the Universidade Federal de Pelotas (UFPel). The proposal arose from the desire to broaden the knowledge about contemporary dramaturgy, that is not widely contemplated in the curriculum of the graduation in Theater of UFPel, since it comprises a wide range of contents, ranging from what is understood by theater in prehistory to contemporaneity. The group intends to study the dramatic literature produced from the end of the twentieth century until present day, performing dramatic readings open to the community (academic or otherwise) in the closure of each study cycle (executed in the small group) of the play and/or author. Before the beginning of this initiative, in the Theater graduation, dramatic readings were not made only for the knowledge of texts with defined periodicity. The purpose of the public readings is to bring to the knowledge of people for existence of the plays and their authors. To this end, the members of the project (all theater academics added to the coordinator, also a theater teacher) are free to organize the ways how texts will be explored. This article intends to investigate the dramatic reading as a point between the dramaturgy as literature and the staging, analyzing the concept of theatricality in the systematization and accomplishment of the dramatic readings performed by the group until then
\end{abstract}

Keywords: contemporary dramaturgy, dramatic literature, dramatic reading, staging, theatricality.

\title{
1. Introdução
}

O presente artigo busca investigar o espaço compreendido entre a dramaturgia e a encenação, que é explorado no projeto de pesquisa "Leituras do drama contemporâneo", da Universidade Federal de Pelotas (UFPel). Buscando articular os conceitos de leitura dramática e teatralidade, serão abordados os objetivos do projeto e os caminhos percorridos antes e depois das duas leituras dramáticas realizadas até agosto de 2016. Introduzindo as ideias pertinentes à discussão da prática do grupo, este trabalho também faz parte do processo de entendimento dos conceitos estudados, que o grupo segue investigando e, portanto, as inferências aqui realizadas são breves e de caráter introdutório ao tema.

O curso de Licenciatura em Teatro da referida universidade tem, contempladas em seu currículo, inúmeras sugestões de leituras de textos dramáticos. Devido à grande quantidade de peças importantes já existentes e que ainda são produzidas, é selecionada apenas uma parcela dessas para serem estudadas durante o curso em leituras obrigatórias. Essa triagem acaba por excluir muitas obras que também são relevantes para o estudo da teoria e história do teatro. 
Visando suprir parte dessa carência e atender ao interesse de alunos por literatura dramática, surgiu, ao fim do segundo semestre de 2015, o projeto de pesquisa "Leituras do drama contemporâneo", coordenado pela Prof. ${ }^{a}$ Dra. Fernanda Vieira Fernandes, compondo o Grupo de Estudos em Teatro: Histórias e Dramaturgias (GETEHD). A pesquisa é composta ainda por seis acadêmicos do curso e se propõe a estudar a dramaturgia produzida a partir do final do século XX até o que se escreve nos dias atuais. $\mathrm{O}$ projeto pretende fazer estudos aprofundados das peças no pequeno coletivo e apresentar leituras dramáticas abertas à comunidade ao fim do ciclo de estudos de cada peça/autor.

A fim de subsidiar a pesquisa do que se entende por dramaturgia contemporânea, os encontros realizados ao fim do segundo semestre de 2015 se voltaram à análise de conceitos que auxiliariam na investigação dos textos. Foram discutidas, entre outras, ideias acerca de drama, teatro pós-dramático, as novas acepções de personagem, enredo, diálogo e outros aspectos inerentes à dramaturgia.

\section{Mosaico Koltès: primeira leitura dramática do grupo}

No primeiro semestre de 2016, na retomada das atividades, escolheu-se o primeiro autor a ter seus textos estudados e posteriormente lidos na primeira prática de leitura dramática do grupo. O escritor selecionado foi Bernard-Marie Koltès (1948-1989). Iniciou-se por esse autor por ser de interesse do grupo trabalhar com textos que são referência na dramaturgia ocidental do final do século XX e também por ter sido o dramaturgo sobre o qual a coordenadora do projeto desenvolveu suas pesquisas de mestrado e doutorado.

Koltès nasceu na cidade de Metz, na França. Sua produção dramatúrgica iniciou na década de 1970 e, até seu falecimento em 1989, conta com quinze peças teatrais. As temáticas de seus textos são reflexo da movimentada vida do autor, marcada por inúmeras viagens que influenciaram a construção de textos preocupados com as minorias, a solidão e a violência. Koltès se mostra sensível aos diferentes lugares pelos quais passou, transformando suas percepções em metáforas a serem postas em cena (FERNANDES, 2011, p.222-223).

Das peças koltesianas, selecionou-se Combate de negro e de cães (1979), Tabataba (1986), Na solidão dos campos de algodão (1987) e Roberto Zucco (1988). Os textos foram lidos e discutidos com o auxílio da teoria sobre o drama contemporâneo estudada em 2015, que enriqueceu o debate ao perceberem-se inúmeras características antes apenas comentadas teoricamente. No contato com os textos, as questões relacionadas ao preconceito e à solidão, entre outras, se mostraram como marca da escrita do autor, que as usando como temática, construiu peças que apresentam certa dificuldade de comunicação entre os indivíduos, como é 
possível perceber em $\mathrm{Na}$ solidão dos campos de algodão, peça na qual as duas personagens têm diálogos tão saturados em seu conteúdo que os levam à incompreensão. São apresentados personagens fragmentados, correspondendo à uma das tendências da dramaturgia contemporânea: a de apresentar os indivíduos sob determinadas perspectivas e não mais tentar mostrá-los em sua completude. Após essas e outras reflexões, partiu-se então para a organização do material a ser apresentado na leitura pública.

O grupo decidiu realizar a leitura de diversos trechos das peças de Koltès. Para isto, os integrantes selecionaram fragmentos pelos quais demonstraram interesse e, depois de elencar as cenas a serem apresentadas, passaram a investigar e criar formas para a execução da leitura dramática, num evento que, por não ser a leitura de uma única peça e sim de vários quadros, foi chamado Mosaico Koltès, apresentado no dia 21 de maio de 2016, em duas sessões, no Núcleo de Teatro da UFPel.

O referido local não é um espaço convencional para práticas teatrais, é uma casa (outrora residencial) com salas amplas, cozinha, banheiro, pátios (interno e externo) e corredores. Todos estes espaços foram utilizados, buscando otimizar o potencial de significado que poderia ser criado nas leituras, levando em consideração qual ambiente poderia ser a melhor opção para cada cena elencada. Durante vários encontros, o foco dos integrantes (sozinhos ou em grupos, dependendo da quantidade de personagens em cena) foi na investigação dos espaços, de objetos cênicos e do corpo e voz para cada cena. Não houve uma direção de cena centralizada em uma pessoa, as construções foram feitas pelos atores que, de acordo com a necessidade, receberam orientação da coordenadora.

Após a segunda sessão, abriu-se espaço para debate com o público sobre as leituras realizadas. É uma das propostas do projeto sempre estabelecer diálogos com os espectadores após as leituras, promovendo conversas a respeito da leitura (uma vez que o grupo está em processo de construção permanente), dos textos e seus autores, sendo este o momento para que o coletivo compartilhe o que se descobre na pesquisa e também ouça as percepções e questionamentos da plateia. Surgiram diversos comentários acerca das soluções cênicas em cada trecho, sobre o conteúdo dos textos de Koltès, sobre a utilização do espaço e tantos outros focados nas sensações despertadas durante as leituras. Entretanto, também houve um questionamento quanto à metodologia com que se compôs o Mosaico Koltès, no sentido de que alguns dos trechos apresentados tinham ultrapassado uma "simples leitura" por apresentarem-se interpretações e contracenações que demandaram que os integrantes tivessem decorado o texto e o abandonado enquanto elemento cênico, assim como acontece em uma encenação. Como contraponto, outro espectador colocou que essa nuance entre momentos de 

e-ISSN 2016/Atual: 2525-7870 | e-ISSN 2015/2016: 2447-018X

um jogo de cena mais elaborado e momentos de uma leitura mais "fria" é interessante por trazer a público parte do que poderia ser um processo de encenação de uma peça.

\title{
3. Do entendimento da leitura dramática e de aspectos de significado do texto
}

A provocação que surgiu no debate com os espectadores é de grande importância para o crescimento da pesquisa, uma vez que o grupo está investigando maneiras de executar as leituras e, frente a esse questionamento, apresenta-se a definição conceitual do que seria uma leitura dramática, encontrada no Dicionário de Teatro de Patrice Pavis:

\begin{abstract}
Gênero intermediário entre a leitura de um texto por um ou vários atores e a espacialização ou encenação deste texto, a leitura dramática usa alternadamente os dois métodos. Lucien ATTOUN explorou esta fórmula no âmbito de seu Teatro Aberto em Avignon e em Paris ou em France-Culture, dando a conhecer textos inéditos ou não representados a um público reduzido e a atores que poderiam montálos em condições mais "cênicas". (PAVIS, 1999, p. 228. Grifo do autor)
\end{abstract}

É necessário que se tenha em mente que os alunos integrantes do grupo de pesquisa são acadêmicos do curso de Teatro e, portanto, possuem forte ligação com práticas cênicas e processos de criação que também tem como fim encenações. Tal característica influi diretamente na construção do formato de apresentação das leituras dramáticas. $\mathrm{O}$ grupo não deixa de lado o objetivo da leitura pública: divulgar à comunidade textos que comumente não são tão conhecidos, sem o compromisso de mostrar um produto finalizado, como em uma encenação. Porém, em função de suas práticas anteriores, sistematizam as leituras de modo diferenciado, com maior teatralidade.

A teatralidade pode opor-se ao texto dramático lido ou concebido sem a representação mental de uma encenação. Em vez de achatar o texto dramático por uma leitura, a espacialização, isto é a visualização dos enunciadores, permite fazer ressaltar a potencialidade visual e auditiva do texto, apreender sua teatralidade. (PAVIS, 1999, p. 372. Grifo do autor)

Nesse sentido, a prática do grupo na realização das leituras, vai de encontro com essa visão dicotômica pela qual se entende que a teatralidade está reservada apenas à encenação. $\mathrm{O}$ grupo faz uso tanto do que Pavis chama de "achatamento" do texto dramático, pela leitura, quanto da espacialização, que ressalta os potenciais do texto, pela busca de jogos cênicos. Essa prática traz à discussão a noção de teatralidade na qual entende-se que: 
É o teatro menos o texto, é uma espessura de signos e de sensações que se edifica em cena a partir do argumento escrito, é aquela espécie de percepção ecumênica dos artifícios sensuais, gestos, tons, distâncias, substâncias, luzes, que submerge o texto sob a plenitude de sua linguagem exterior. (BARTHES, 1964, p. 41-42 apud PAVIS, 1999, p. 372)

Anne Ubersfeld questiona essa concepção, visto que é arbitrário reservar a teatralidade apenas à representação. É necessário que se entenda que tanto os signos textuais quanto os signos próprios da representação são considerados para que o discurso seja transmitido pela comunhão destes. A efetividade dessa transmissão provém da união da sintaxe textual e da relação proxêmica (pesquisa que se ocupa das relações humanas em função da proximidade física) da representação, ou seja, da união, na cena, daquilo que é dito com as ações das personagens (UBERSFELD, 2005, p. 5).

Poderia se falar então na criação de um novo campo que abriga a prática do projeto? $\mathrm{O}$ objetivo de levar textos ao conhecimento da comunidade dá liberdade ao grupo para propor leituras que tanto se aproximam de uma leitura calcada apenas no trabalho de voz, quanto no uso de recursos mais próximos da encenação. A liberdade de trabalho nessa lacuna faz com que se pense nas leituras públicas das peças como uma força que engendra uma nova noção de teatralidade reservada ao modo de ler proposto a cada leitura, pois as decisões feitas no que tange à forma de mostrar as relações estabelecidas entre as personagens influenciam diretamente na recepção por parte do espectador que tem acesso ao texto com a mediação dos atores.

O texto teatral não prescinde da encenação para ser esclarecido. Quando, na busca pelo entendimento de uma peça, diz-se que ela é um documento textual cujo significado completo está fora de suas páginas, crê-se que as lacunas de sentido existentes na análise do texto serão preenchidas na representação. O que é não é um raciocínio de todo errôneo, mas ingênuo.

A análise do texto e a análise da representação são processos diferentes, complementares e não interdependentes. A ingenuidade do raciocínio exposto acima reside no fato de que a materialização do texto em uma encenação não vai necessariamente preencher as lacunas do texto. A encenação encontra-se na posição de eximir-se do preenchimento dos "buracos" do texto, assim como tem a liberdade de abrir questões que antes pareciam já resolvidas. Lehmann (2011) sinaliza que a representação cênica de uma peça no teatro que ele denomina pós-dramático liberta-se completamente da tentativa de explicar ideias de um autor ou encerrá-las. O textocentrismo, vigente até o século XX, perde força e dá igualdade aos 
diversos elementos que compõem uma encenação. Ou seja, desaparece a necessidade de dar sentido fechado a uma peça a partir da sua representação.

Pode-se inferir que a independência dos dois tipos de análise - do texto e da representação - se deu pelo constante processo de atualização do teatro. Quando, em cena, os atores passam a executar ações dissociadas do sentido do texto, para evitar redundância, no papel, o dramaturgo passa a entender que a ação é inerente à representação e que o dizer é matéria do texto.

\section{4. Ânsia: a segunda leitura dramática no projeto}

A leitura dramática seguinte foi da peça Ânsia (1998) da dramaturga inglesa Sarah Kane (1971-1999). A autora é, assim como Koltès, um dos expoentes na dramaturgia contemporânea do fim do século XX, mesmo tendo apenas cinco peças publicadas. Kane escreveu textos que não estão em consonância com a produção de escrita britânica de sua época, com grande foco no psicológico das personagens e rompendo com as convenções da forma de escrita da dramaturgia, trazendo imagens fortes e agressivas. Sarah Kane tinha problemas psicológicos graves que chegam a ser retratados em suas peças, foi internada em clínica psiquiátrica, tentou suicídio sem êxito tomando medicamentos, até que em 20 de fevereiro de 1999 é encontrada morta - havia se enforcado.

Ânsia não tem uma história com início, meio e fim e não apresenta personagens, mas presenças que estabelecem diálogos que fogem ao usual, parecendo experimentos com a linguagem. Diferentemente das peças de Koltès, que mantém, de certa forma, certa coerência direta nos diálogos e apresenta, na maioria das vezes, personagens mais "tradicionais". A peça foi escolhida justamente por fazer correspondência a diversos dos conceitos teóricos vistos em 2015 e também por ser extremamente desafiadora para o grupo de pesquisa.

A tradução do título da peça em língua portuguesa no Brasil é “Ânsia”, já em Portugal, traduziu-se por "Falta". No original, Crave, do inglês, que pode ser traduzido como "precisar", "desejar", "suspirar por”. O título carrega as diversas possibilidades de leitura que convergem para a temática da peça, que permeia violência, ansiedade, morte, estupro, melancolia e dor. Os inúmeros sentimentos, sensações e imagens evocadas pelo texto de Kane fizeram com que se usasse menos recursos cênicos (tanto em se tratando de ações, quanto em objetos) do que na leitura dramática anterior, pois, após algumas experimentações, o grupo percebeu que o interessante a ser explorado nessa leitura seria o ritmo do texto. Em grande parte dele as vozes (forma como referimo-nos aos diferentes enunciadores de discurso do texto - na peça, são diferenciados pelas letras: A, B, C e M) têm falas curtas que estabelecem 

e-ISSN 2016/Atual: 2525-7870 | e-ISSN 2015/2016: 2447-018X

um ritmo marcado ao texto que, em alguns momentos, é cortado por algum monólogo ou um texto mais longo de alguma delas. As falas não são estruturadas como em um diálogo tradicional, embora em alguns momentos pareçam conversar entre si, as vozes são como existências independentes, cujas histórias podem apenas ser cotejadas. Não há como inferir com segurança a identidade, os desejos e destinos dessas vozes que parecem fazer referência à patologia psíquica da autora.

A peça possui apenas breves e poucas indicações dadas nas rubricas, reservando-se apenas a indicar silêncios ou sobreposição de falas. É um exemplo do processo comentado acima, no qual o dramaturgo não mais se preocupa com a ação a ser executada pelos atores, mas sim com o discurso a ser proferido verbalmente. Seguem exemplos das poucas indicações dadas pela autora:

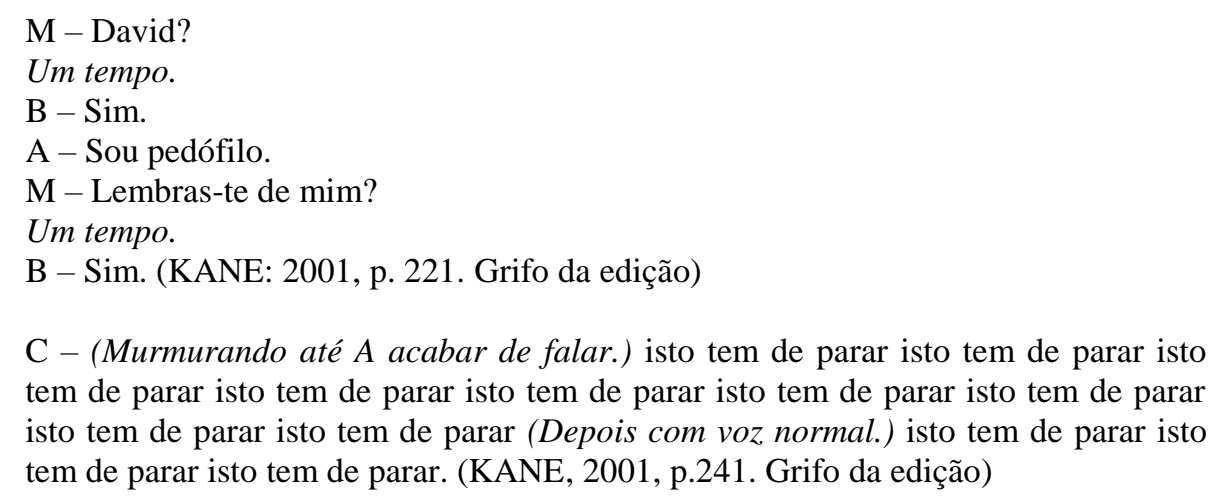

Em uma dramaturgia tão aberta quanto a desta peça, ficam pouco evidentes, nas primeiras leituras, as ações a serem executadas e é no trabalho prático com o texto que se podem experimentar e descobrir aspectos antes não trabalhados ou descobertos. Em sua dissertação de Mestrado em Artes Cênicas realizada na Escola de Teatro e Dança da Universidade Federal da Bahia, Gideon Alves Rosa desenvolveu oficinas para preparação de atores para realização de leituras e, ao discorrer sobre a potencialidade de revelação dos textos dramáticos a partir da prática da leitura dramática, observa:

Um ator (e um diretor mais ainda) deve saber que o texto desencadeia e exige ações e reações específicas. Isso não significa que o ator, no percurso da leitura, as execute, mas sim, que ele brinque com a possibilidade, dentro do seu discurso, do impulso físico de ação e reação que as circunstâncias do teatro exigem. Assim, assistimos, durante uma leitura eficiente, o ímpeto de partituras inteiras de ações físicas esboçadas, mas ainda não executadas. (ROSA, 2006, p. 56-57)

A leitura foi ensaiada e apresentada em uma sala ampla do Casarão 8 - Museu do Doce, prédio da UFPel, patrimônio histórico de Pelotas/RS, localizado na Praça Cel. Pedro 
Osório, no Centro da cidade. A sessão aberta ao público ocorreu no dia 28 de agosto de 2016. A proposta para esta leitura era investir no ritmo do texto e das palavras, com esse objetivo, foi disposto um grande número de cadeiras espalhadas por toda a sala, utilizando-as também como cenografia. Mais uma vez o grupo desafiou-se a utilizar espaços cênicos não convencionais e refletir de que forma este espaço traria outras sensações ao público. Os espectadores tinham liberdade para sentar onde quisessem, entendendo que estariam "dentro" da leitura, uma vez que não havia uma divisão tradicional entre palco e plateia. Para os atores, a dinâmica tinha propósito objetivo: manter-se no ritmo do texto e executar ações que fossem pertinentes, mas que não tirassem o foco do que estava sendo lido/dito.

Após a leitura ocorreu o bate-papo com os espectadores. Alguns comentaram terem fechado os olhos durante a leitura, percebendo o texto realmente como vozes dentro da própria cabeça. Comentou-se também sobre a relação de proximidade que existia entre atores e público, uma vez que a disposição das cadeiras no espaço possibilitou que, vez ou outra, os atores tocassem nos espectadores, sussurrassem em seus ouvidos, sentassem à sua frente. Percebeu-se o quão desafiador foi essa leitura por propor que o espectador focasse sua atenção em ouvir, já que que as ações realizadas eram muito sutis e deixavam o foco da apresentação voltado para o texto.

\section{Considerações Finais}

Historicamente, a prática de leituras públicas é feita para a divulgação de novos textos. A leitura dramática de peças teatrais, além deste propósito, possui um grande potencial enriquecedor em um processo de encenação que assume sua construção a partir de um texto pré-existente. $\mathrm{O}$ que se descobre sobre a obra literária e sobre as relações entre as personagens na prática da leitura dramática está em outra via que não pertence à análise dramatúrgica, mas sim nas relações que são percebidas ao experimentar, na prática, as potencialidades do que está presente no texto escrito.

A encenação de peças não é um objetivo no projeto de pesquisa "Leituras do drama contemporâneo". O que o grupo se propõe a fazer é investigar a dramaturgia da atualidade e compartilhar com o público em geral e especialmente com os artistas e estudantes de teatro, abrindo ainda mais o grande leque de possibilidades a serem trabalhadas em cena. No momento das leituras públicas, a metodologia de trabalho empregada pelo grupo se dá na busca por revelar o potencial de criação de imagens que estão presentes no texto. Explora-se, na construção da leitura dos quadros ou cenas, possibilidades de colocar em ação aquele texto que antes estava apenas reservado ao papel. 
Em virtude de o foco da pesquisa do grupo ter sido a dramaturgia e a teoria do drama contemporâneo, pouco material sobre leitura dramática foi pesquisado e encontrado até o momento, portanto as primeiras experiências do grupo podem ter sido executadas de modo “empírico". A coordenadora do projeto vem há algum tempo experimentando a proposta de descoberta da literatura dramática através de seu estudo e posterior leitura pública. Sejam elas experiências anteriores, como o projeto "Dramatúrgicas", desenvolvido na cidade de São Leopoldo/RS, ou do projeto de extensão da UFPel, Teatro em Francês, que executa leituras dramáticas na referida língua estrangeira com estudantes do curso de Letras.

O grupo de pesquisa "Leituras do drama contemporâneo" entende que a experimentação das possibilidades que os textos dramáticos suscitam não desqualifica as leituras dramáticas realizadas até então. Pelo contrário, a prática do grupo, ao explorar as questões que são reveladas no trabalho com as peças vem ao encontro do que se espera ver em cena, uma pluralidade de signos que podem estar contidos no texto ou descobertos no trabalho concreto com ele.

A produção deste artigo converge para as práticas que estão sendo realizadas na pesquisa, ao articular, numa primeira abordagem teórica, os conceitos de leitura dramática e teatralidade com as atividades realizadas até então. Por ser um estudo inicial, as questões aqui levantadas continuarão a ser investigadas nas próximas práticas e produções escritas do grupo.

\section{Referências}

FERNANDES, F. V. O personagem negro na literatura dramática francesa do século XX: La Putain respectueuse, de Jean-Paul Sartre, e Combat de nègre et de chiens, de Bernard-Marie Koltès. 2014. 234 f. Tese (Doutorado em Letras) - Programa de Pós-Graduação em Letras, Universidade Federal do Rio Grande do Sul, Porto Alegre, 2014.

. Antagonismo de olhares: embates na recepção de Roberto Zucco, peça teatral de Bernard-Marie Koltès. Cadernos do IL, Porto Alegre, UFRGS, no 43, 2011. Disponível em: http://seer.ufrgs.br/index.php/cadernosdoil/article/view/25320/pdf. Acesso em $10 \mathrm{de}$ novembro de 2016.

KANE, S. Teatro completo. Tradução de Pedro Marques. Porto: Campo das Letras, 2001.

OLIVEIRA, L. S. de. Crave: uma análise do procedimento pós-dramático de Sarah Kane. Cena, Porto Alegre, UFRGS, $n^{\circ}$ 15, 2014. Disponível em: http://www.lume.ufrgs.br/handle/10183/131258. Acesso em: 10 de novembro de 2016.

PAVIS, P. Dicionário de teatro. Trad. sob a direção de J. Guinsburg e Maria Lúcia Pereira. $2^{\mathrm{a}}$ ed. São Paulo: Perspectiva, 1999. 

e-ISSN 2016/Atual: 2525-7870 | e-ISSN 2015/2016: 2447-018X

ROSA, G. A. Leitura Dramática: um recurso para revelação do texto. Dissertação (Mestrado em Artes Cênicas) - Programa de Pós-Graduação em Artes Cênicas da Escola de Teatro e Dança, Universidade Federal da Bahia, Salvador, 2006

RYNGAERT, J.-P. Introdução à análise do teatro. Trad. Paulo Neves. São Paulo: Martins Fontes, 1995.

SARRAZAC, J.-P. (org.). Léxico do drama moderno e contemporâneo. Trad. André Telles. São Paulo: Cosac Naify, 2012.

UBERSFELD, A. Para ler o teatro. Trad. José Simões. São Paulo: Perspectiva, 2005. 